\title{
Research on How to Give Different Sculptures Different Souls through Different Materials
}

\author{
Yujiu Liu \\ Ningxia Normal University, Art School, China, 756000
}

Keywords: Sculpture; Material; Soul; Emotional Expression; Art

\begin{abstract}
With the rapid development of the times, the sculpture materials are constantly developing and updating, which gives the sculpture creation more room for growth. The connotation of sculpture works is that the artist shows his soul, thoughts and emotions to the people through a third party, and the third one is the factor of things. With the continuous development of sculpture materials, sculptors have more choices of emotional support when creating works. Through different sculpture materials, they can express different emotional thoughts. In this context, it is necessary to give different materials the different souls of sculptures, which is conducive to promoting the art field more colorful.
\end{abstract}

\section{Introduction}

With the rapid development of China's economy and society, the development of information technology and materials engineering science in China is changing with each passing day. Under this background, sculpture materials are also constantly enriched and innovated, which makes the sculpture art have a broader development space. As our culture continues to develop, the art of sculpture is becoming more detailed and diverse, and the relationship between sculpture materials and the soul of sculptures is gradually changing. The author puts forward the understanding of the different souls given to the sculptures by different materials in combination with their own feelings and ideas, and hopes to have reference significance for the people in the sculpture industry.

\section{Overview of the Development History of Sculpture Materials}

In the long history of China's historical development, sculptures have been born since the Paleolithic Age, and the sculpture materials have achieved fruitful results along with the development of the times. In the process of the development of human history and civilization, sculptures of many material elements such as pottery, bronze, iron, silk, porcelain, gold and silver were born. With the development of contemporary civilization, new materials such as glass, plastic, paper, steel and fiber have also been widely used, which has laid a good foundation for the development of social pluralistic culture. Therefore, research and application of materials have very important practical significance for human history.

In China's primitive era, most of the earliest engraving art materials used in China were stoneware, jade and bones. We are generally called sculpture works. These works are constantly formed in people's long-term exploration life; it is a rough stoneware, or a container constructed of soil and wood. The shaping and carving of these works can also reflect the development of people's life at that time, so it has a very high research value [1].

\section{An Overview of the Classification of Sculpture Art Forms}

In a sense, there is no unified model for the form of sculpture art. In many cases, sculptors use materials, forms, and spatial relationships as the direction of sculpture research. Along with the development of society, more and more art has entered the hall of art in the name of "sculpture", such as wrapped sculpture, conceptual art, performance art, waste sculpture and installation art. In the post-modern art, the use of materials has become more extensive, and related sculpture 
designers have also used "materials" as the most direct expression medium for art. Therefore, modern materials have a very high independent appreciation value and visual experience, which plays an irreplaceable role in our future research and development. An overview of the main categories of sculpture art forms is now available:

This type of sculpture has a history of about a hundred years. The soul of the constitutive sculpture is Gabor. He was involved in the analysis of cubism and comprehensive thematicism in his youth. His personal concept is very significant; he boldly uses thin metal sheets. Combined with cardboard, it fully demonstrates the way social exclusion and active space are expressed at the time [2].

In the 1920s, Hungary's Moholinaji put his gaze more into related elements such as light, space and sports, and she was also known as the founder of mechanized activity sculpture. In his work, more attempts are made to incorporate real movements, and the actual influence of light on sports sculptures is also very important. Therefore, it can be said that her research on the influence of light in sports sculpture is very creative. In her works, her thoughts can be fully expressed. The light projected by the works can be closely related to the space, and finally form a Complete overall.

Behavioral sculpture art, if analyzed from a conceptual point of view, mainly refers to the process by which a painter or sculptor recreates by using some of the scrapped things in daily life. For example, many sculptors in Western countries use such old newspapers, train tickets, multi-resin and some mixed materials as the main materials to construct sculpture art, which is one of the most prominent features of Western contemporary sculpture [3].

Incorporating the sculptor's rich and abstract imagination into the sculpture is an emotional expression. The minimalist form of sculpture art is the opposite, and there is no form of emotion, it is merely to satisfy the state of form. Judging from the works of some of them, the author has canceled the problem of "self-expression" and can't see the relevant traces at all. The basic idea is that standard art should express rational order, clear and rigorous concepts, simplified forms and other forms of art that are non-moral and non-literary.

\section{The Use of Low Carbon Sculpture Materials}

Sculpture materials have a great effect on the decorativeness of space, and also have important significance in the arrangement of places and the expression of human spiritual connotations. Along with the accelerating pace of global urbanization, we have begun to pay attention to the use of environmentally friendly low-carbon materials in many areas of our daily production and life. More people are paying attention to the path of sustainable development such as reducing consumption, energy saving and emission reduction. In the aspect of landscape design, the selection and application of materials for sculptural works began to adopt low-carbon materials. This is also the waste sculpture art expression mentioned above. The low-carbon materials will be reused for waste, not only for landscapes. Sculpture design, but also contribute to the cleanliness of the environment.

With the continuous innovation and development of science and technology, many artists use low-carbon materials as a new element in landscape sculpture design, and then incorporate contemporary technology into their works, constantly enriching the abstract meaning of materials and truly embodying landscape sculpture. [4]. For example, in the 20th century, the soul of the sculptor, Calder, is actively exploring the use of low-carbon materials, such as daily abandoned water pipes, steel pipes and other simple materials to create a lot of abstract sculptures. The form gives people a refreshing feeling. The use of low-carbon sculpture materials is a great artistic innovation for contemporary sculpture art. The use of low-carbon materials not only makes the sculptures have a more unique artistic beauty, but also plays a positive role in the environment and society.

\section{Different Materials Give Different Souls to Sculptures}

The formation of artworks is mainly from people's thoughts and emotions. By expressing their thoughts and emotions through specific ways and contents, they form a work of art. Therefore, the 
simple copying of objective things does not belong to artistic creation. The real artistic creation should reflect people's thoughts and feelings and emotional sustenance. In the long history of artistic creation, people always emphasize the endowment of the soul and feelings of art. In fact, it is what we call "the slogan" or "sense". The same is true for sculpture art. People express their emotions and vitality through sculpture forms and sculpture contents, and the form of the soul of sculpture works is sculpture material. As time goes by, the feelings that people give to sculpture materials are different. Therefore, the souls of sculptures given by different materials are also different. In ancient times, people usually used ceramics and bronzes to make sculptures. This sculpture material gave the sculptures more of a soul that aweed nature and admired nature. After the end of the ancient Greek period, the master of sculpture Rodin broke the "standard beauty". The shackles express their unique personal thoughts and emotions through bronze sculpture materials. In modern times, the sculptural art expressions are rich and varied, and different sculpture materials endow the sculptures with different values, emotions and soul thoughts. It is not difficult to find that materials have always been an important tool for the soul of sculptures, no matter when, no matter how people's emotions, thoughts and aesthetics change. Only by accurately understanding the material texture, the material texture, and the culture represented by the material can the sculptor accurately reflect the soul of the sculpture through the material.

As a touch of art, sculpture has a very close relationship between texture and texture. In order to give their thoughts and emotions, the artist must accurately understand the material texture when performing sculpture. The material texture mainly includes three forms: one, natural texture, mainly refers to the natural texture without the artist's treatment, such as the annual rings in the stump and the natural texture on the stone; Second, the artificial texture, mainly refers to the artist carving The texture of the processed material, for example, the texture of the material formed by the process of cutting, coloring, pouring, distressing, imprinting, grinding, etc., which reflects the sculptor's own thoughts; third, the artist changes the material artistic sense. The material texture formed, for example, the artist Henry Moore enhances the expressive power of the artwork by sculpting some traces of the sculpture. So, how do different textures of different materials give different souls to sculptures? First, the texture of the sculpture material can highlight the theme of the sculpture. Each sculpture will have a theme of the work. The theme is often the soul of the sculpture. In the process of setting and rendering the theme, it is necessary to apply the material texture, such as the sculpture of the sculptor Zadkin [5]. Second, the sculptural material texture can express the sculptor's emotions, such as the sculptor Giacometti, who likes and is good at sculpting character works. In sculpture, he often likes to use the overall sculpted texture to give the vicissitudes of life and mottled soul. Third, the texture of the sculptural material can enhance the expressiveness of the sculptural works. For example, the sculptor Brancusi's masterpiece "Bogani Group" uses bronze sculpture materials and combines metal polishing techniques to deal with the texture of the work. The texture makes the work full of three-dimensional and vivid, in which people can feel the visual impact of the work when they watch the work. Finally, the texture of the sculpture material can enhance the touch of the work. By touching the texture of the sculpture surface, we can feel the soul represented by the work.

The texture is the feeling of the material of the sculpture. The different textures of different sculpture materials give different souls to the sculpture. For example, the use of delicate, simple wooden sculpture materials can give the sculpture a straightforward and vicissitude soul; the use of transparent glass sculpture materials can give the sculpture a clean, clear and bright soul; the use of solid and heavy metal sculpture materials can give the sculpture A reliable, thick soul; using modern fiber sculpture materials can give the work a close, pleasant, warm soul. The texture of the material can be judged not only by direct touch, but also by the visual impact of the person. For example, some rough and difficult material textures often bring a dull and confused mood; while some soft, delicate or crystal material textures will bring softness or warmth to people.

Contemporary sculptors will pay more attention to the texture of materials. For example, in the famous sculpture master Brancusi's "The Bird of the Air", it can be seen that it retains the characteristics of the stone and the metal itself while strengthening the image. The aspect is more 
prominent, which can strengthen the overall expressiveness of the sculpture. Moreover, Brancusi has carefully polished and polished these materials to make these texture properties more prominent. In addition, many sculptors today also use some comprehensive materials. For example, for some metal materials, some contemporary sculptors will carry out in-depth and bold excavation, fully study the aesthetic value of the texture of the sculpture material, and give full play to the material texture.

\section{Conclusion}

In summary, the most intuitive expression of the soul of sculpture art is realized through materials. The types of sculpture materials are very rich, and they all have their own unique characteristics. Emotions must be controlled to understand the character of the sculpture material. Only by fully understanding and understanding the character of the sculpture material can it be fully utilized so that different materials can be used to give different souls to the sculpture art.

\section{References}

[1] Zhang Haonan. Sculpture-material interaction with emotion [D]. Hebei Normal University, 2013.

[2] Zhang Ke. The negative impact of material abuse on sculpture art [D]. Xi'an Academy of Fine Arts, 2016.

[3] Zhu Tao. Research on the aesthetic value of sculpture materials and environment [D]. Xi'an University of Architecture and Technology, 2013.

[4] Li Shuai. The use of materials in sculpture works and unique artistic language [D]. Harbin Normal University, 2012.

[5] Hu Yining. Research on sculpture creation based on emotional expression of comprehensive materials [D]. Hubei Academy of Fine Arts, 2018. 